\title{
Virtual Instrumentation in Biomedical Equipment
}

\author{
http://dx.doi.org/10.3991/ijoe.v9iS1.2283 \\ T. F. Andrade ${ }^{1}$, M. R. Quintas ${ }^{1,2}$, C. M. Silva ${ }^{1,2}$, M. T. Restivo ${ }^{1,2}$, M. F. Chouzal ${ }^{1,2}$ and T. M. Amaral ${ }^{1,3}$ \\ ${ }^{1}$ UISPA/IDMEC-Pólo FEUP \\ ${ }^{2}$ Faculdade de Engenharia, Universidade do Porto \\ ${ }^{3}$ Faculdade de Ciências da Nutrição e Alimentação, Universidade do Porto
}

\begin{abstract}
At present the world increase of overweight and obesity in parallel with undernutrition has a great impact in many fields such as nutrition, health, sports, chronic diseases and others. Because of this the assessment of body fat became more and more required. An easy, non-invasive and portable method based in the measurement of skinfolds uses skinfold callipers and makes possible the estimation of the percentage of body fat.
\end{abstract}

The callipers recognised in the literature and available in the market lack technological evolution.

A novel integrated system has been developed. It consists in a mechanical solution capable of bidirectional wireless communication with a software application running in a personal computer, integrating a database.

The main purpose for this work is to briefly describe the development of a virtual instrument for more effective assessment of body fat, automatic data processing, recording results and storage in a database, with novel features.

Presenting the better mechanical characteristics in the market, offers a friendly user interface and a good transmission rate for the wireless communication between device and software with high potential to conduct new studies in the development of new models based in the time response of adipose tissues, http://lipotool.com.

Index Terms - virtual instrument, wireless communication, biomedical equipment, medical diagnosis.

\section{INTRODUCTION}

Today, the assessment of body composition by estimating the percentage of body fat has a central importance in health. The percentage of body fat is a relevant parameter for assessing the nutritional status [1] of an individual, in the evaluation of growth, in analysing disease impact, in studying the evolution of chronic diseases as is the case of patients under dialysis [2], in sports, in older adults, etc.

There are distinct techniques involving sophisticated and expensive equipment, frequently invasive and expensive. The method based in the use of skinfold callipers offers simplicity (portability, ease of use and not requiring special individual preparation), is non-invasive and low cost, and provides reliable results compared with the gold standard.

The assessment method based in skinfold measurement has well-defined protocols. However, the callipers recog- nised in the literature and available in the market lack technological evolution [3].

The present software and hardware technology which will be briefly described can improve the use of virtual instrumentation for facilitating nutritional assessment with better accuracy and novel features using the skinfold calliper methodology, http://lipotool.com.

Therefore, the aim of this work is to describe a virtual instrumentation, named LipoSoft, embedded in an integrated solution (LipoTool). It permits a more effective assessment and the quantification and screening of individuals in a large scale, with improved accuracy and allowing automatic data processing and recording in a database. The LipoTool also permits to follow the dynamic tissue response when a sinkfold is under compression. Studies based in these features will be used for identification of model elements by using artificial neural networks (ANN) to approximate the time response of adipose tissues or by considering how this time response can be approximated by the behaviour of typical dynamical systems. This allows conducting completely new studies. In fact, section 4.3 shows an example of the information recorded during a skinfold measurement procedure studies. This integrated system consists in a mechanical device (Adipsmeter) for measuring skinfold thickness, capable of bidirectional wireless communication with a software application (LipoSoft) running in a personal computer, integrating a database.

\section{LIPOTOOL - INTEGRATED SYSTEM}

The existing systems using skinfold calliper assess body composition but suffer from various limitations and shortcomings, namely accuracy in the data collecting process and storage and in mechanical features.

In order to overcome many of these problems a new integrated system, named LipoTool, Fig.1, was designed and developed. It consists of a digital skinfold calliper (Adipsmeter) for measuring skinfold thickness, capable of bidirectional wireless communication with a personal computer software application (LipoSoft), integrating a database.

\section{ADIPSMETER - DigITAL SKINFOLD CALLIPER}

Adipsmeter, Fig. 2, is a skinfold calliper, a digitally instrumented device developed in order to measure skinfold thickness and its dynamic response under compression. The skinfold calliper interacts with a software application, LipoSoft, and has novel technical characteristics when compared with those in the market. 


\section{VIRTUAL INSTRUMENTATION IN BIOMEDICAL EQUIPMENT}

\section{LIPOSOFT - VIRTUAL INSTRUMENT}

The virtual instrument LipoSoft, Fig. 3, is an application which offers a user friendly graphical interface organized in three blocks: the database, the measurement and results blocks, making it intuitive and informative, very suitable for training purposes, as well.

\section{A. Database Block}

The Database Block, Fig. 4, allows searching and data updating of individual files, as well as any new registration. In the database all the skinfold thickness measurement along the protocol time are also recorded as well as computed results.

\section{B. Measurement Block}

In the Measurement Block, Fig. 5, a body picture is presented and a red dot pinpoints the location of the skinfold under measurement between the selectable skinfolds. It is possible to make up to three thickness measurements of any skinfold and edit each one of them. During the measurement of each skinfold, the operator error between each measurement is available, too.

\section{Results Block}

The Results block, Fig. 6 offers to the technician different equations for the calculation of the percentage of body fat. When the operator selects a method and an equation, the software automatically informs the skinfolds needed to calculate the percentage of body fat. A picture provides a graphic idea of the evaluated body fat by using the colour associated to the reference values.

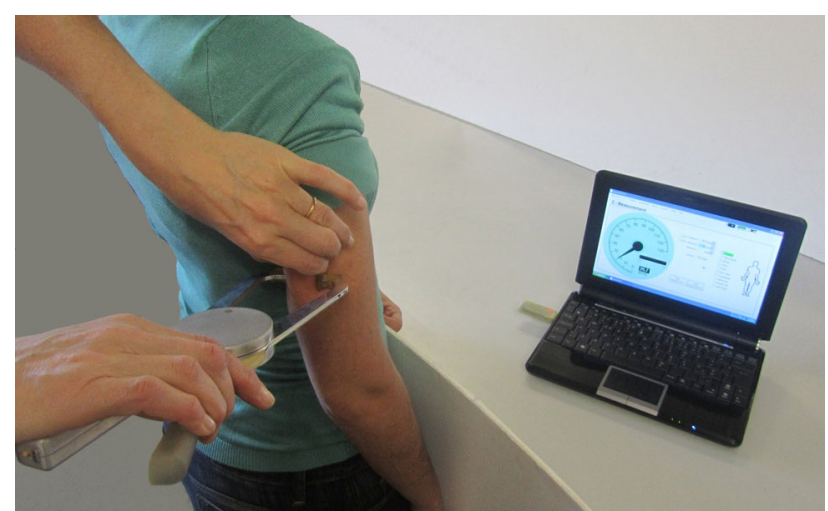

Figure 1. LipoTool, an integrated system for body fat assessment.

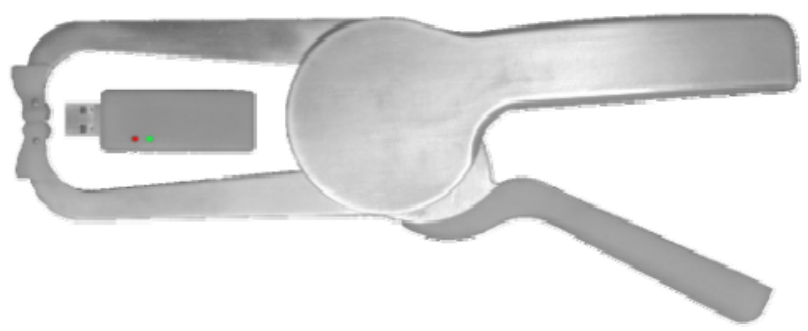

Figure 2. Adipsmeter, a digital skinfold calliper.

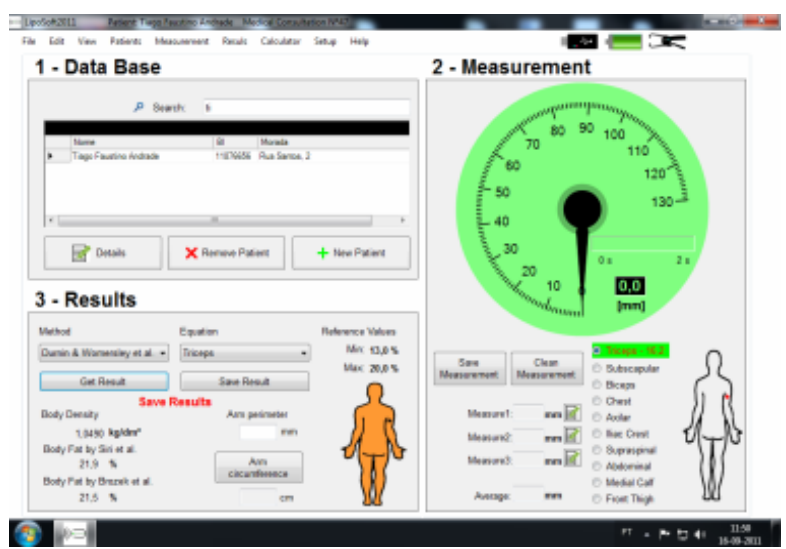

Figure 3. LipoSoft Virtual Instrument.

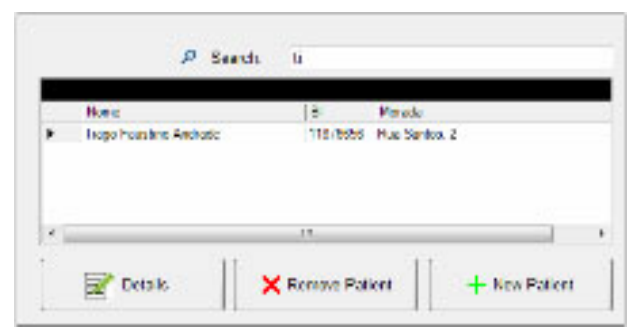

Figure 4. LipoSoft Database Block.

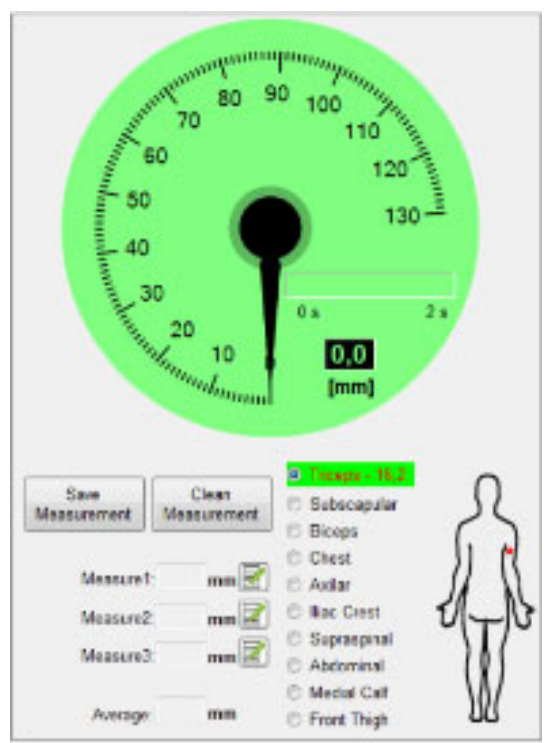

Figure 5. LipoSoft Measurement Block.

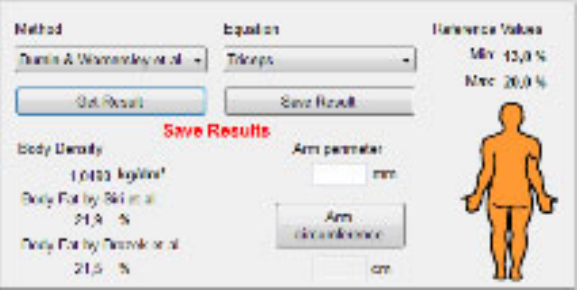

Figure 6. LipoSoft Result Block. 


\section{VIRTUAL INSTRUMENTATION IN BIOMEDICAL EQUIPMENT}

\section{Wireless Communications}

The module used for wireless communication was the MRF24J40MA from microchip and the protocol implemented was the MiWi P2P. The module has low power consumption, is low cost and has approvals in the United States, Canada and Europe. The MiWi protocol results from IEEE 802.15.4 simplification, mainly in the handshaking process.

The good transmission rate achieved for the wireless communication between the calliper and the software (60 samples/s) makes it possible to register the dynamic tissue response of a skinfold under compression (in the case of a tricipital skinfold), Fig. 7, [4].

\section{FINAL DISCUSSION}

The LipoSoft is a virtual instrumentation that permits to the integrated system (LipoTool) to be the more effective body composition assessment tool with high accuracy, allowing automatic data processing and recording in a database. It offers to the user easy manipulation and it does not require technicians with high degree of expertise. It is very convenient for training purposes and for new studies in research activities. The system demonstrated at Exhibition Session@REV2012, got a silver medal in the 40th International Exhibition of Inventions of Geneva, 18 - 22 April 2012 [5] and has two patents pending (at national and international level) [6-7].

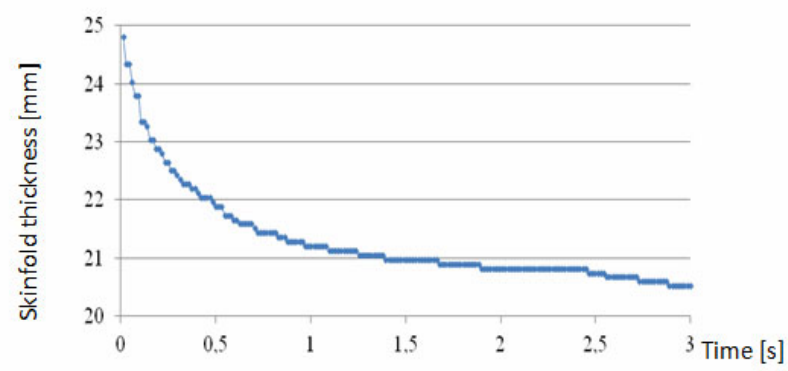

Figure 7. Tricipital skinfold dynamic tissue response

\section{ACKNOWLEDGMENTS}

The present work is due to the development and innovation activities in UISPA within IDMEC Pólo FEUP and LAETA, both funded by National Science Foundation (FCT) and it was also supported by University of Porto.

\section{REFERENCES}

[1] Maria T. Restivo, Teresa F. Amaral, Maria F. Chouzal, Celina P. Leão, Rita S. Guerra, Elisa Marques, Joaquim Mendes, Manuel Quintas and Jorge Mota “A digital Calliper for training and study purposes”, in print in Asia Pacific Journal of Clinical Nutrition.

[2] Coroas, A.S., Oliveira, J.G., Sampaio, S., Borges, C., Tavares, I., Pestana, M., Almeida, M.D. (2005) Sequential body composition analysis by bioimpedance early post kidney transplantation. Transplant International; 18:541-547. http://dx.doi.org/10.1111/ j.1432-2277.2005.00086.x

[3] D. A. W. Edwards, W. H. Hammond, M. J. R. Healy, J. M. Tanner and R. H. Whitehouse. Design and Accuracy of Calipers for Measuring Subcutaneous Tissue Thickness. Br J Nutr. 1955;9(2):133143. http://dx.doi.org/10.1079/BJN19550021

[4] T.F. Andrade, M.R. Quintas, C.M. Silva, M.T. Restivo, M.F. Chouzal, T. M. Amaral, Wireless Communication Solution for Health Care Equipment, Sensors \& Transducers Journal, Vol. 142, Issue 7, July 2012, pp. 95-104.

[5] Awards, http://lipotool.com/ (assessed in October 2012).

[6] National Patent, http://lipotool.com/ (assessed in October 2012).

[7] International Patent, http://lipotool.com/ (assessed in October 2012).

\section{AUTHORS}

T. F. Andrade, M. R. Quintas, C. M. Silva, M. T. Restivo, M. F. Chouzal and T. F. Amaral are with the Research Unit UISPA, IDMEC-Pólo FEUP, Rua Dr. Roberto Frias, 4200-465 Porto, Portugal. E-mail: \{tfa, mrq, csilva, trestivo, fchouzal\}@fe.up.pt and tamaral@fcna.up.pt

This article is an extended and modified version of a paper presented at the International Conference on Remote Engineering \& Virtual Instrumentation (REV2012), held at University of Deusto, Bilbao, Spain, July 4-6, 2012. Received 17 September 2012. Published as resubmitted by the authors 18 December 2012. 